BULLETIN Bulletin hispanique

HISPANIQUE Université Michel de Montaigne Bordeaux

118-2 | 2016

Varia

\title{
Francisco Javier Díez de Revenga, Los poetas del 27: tradiciones y vanguardias
}

Universidad de Murcia, Murcia, 2015

Jacques Issorel

\section{CpenEdition}

\section{Journals}

Édition électronique

URL : http://journals.openedition.org/bulletinhispanique/4693

DOI : 10.4000/bulletinhispanique.4693

ISSN : $1775-3821$

\section{Éditeur}

Presses universitaires de Bordeaux

Édition imprimée

Date de publication : 15 décembre 2016

Pagination : 749-751

ISBN : 979-10-300-0125-9

ISSN : 0007-4640

\section{Référence électronique}

Jacques Issorel, «Francisco Javier Díez de Revenga, Los poetas del 27: tradiciones y vanguardias », Bulletin hispanique [En ligne], 118-2 | 2016, mis en ligne le 15 décembre 2016, consulté le 23 septembre 2020. URL : http://journals.openedition.org/bulletinhispanique/4693 ; DOI : https://doi.org/10.4000/ bulletinhispanique.4693

Ce document a été généré automatiquement le 23 septembre 2020

Tous droits réservés 


\section{Francisco Javier Díez de Revenga, Los poetas del 27: tradiciones y vanguardias}

Universidad de Murcia, Murcia, 2015

Jacques Issorel

\section{RÉFÉRENCE}

Francisco Javier Díez de Revenga, Los poetas del 27: tradiciones y vanguardias, Murcia, Universidad de Murcia, 2015, 520 p.

1 Cet ouvrage est de nature différente de celui décrit plus haut. Offert à Francisco Javier Díez de Revenga par l'université de Murcie, où il fut d'abord un étudiant très tôt remarqué par le regretté Mariano Baquero Goyanes, avant de devenir lui-même enseignant, ce «libro jubilar», comme l'appellent Ana L. Baquero, Francisco Florit et Mariano de Paco dans une brève préface, réunit vingt-quatre études publiées par l'auteur au cours de sa carrière. Celles-ci concernent la «dialéctica tan fructífera » que les poètes de 27 surent établir non seulement avec les grands auteurs du Siècle d'Or mais aussi avec les poètes médiévaux et ceux du XIX siècle. Six études proposent une thématique commune à plusieurs des huit poètes étudiés. Ainsi le Moyen Âge est-il présent, entre autres, chez Pedro Salinas, auteur d'une version moderne en vers hexadécasyllabes du Poema de Mio Cid (p. 19) et chez Gerardo Diego, qui composa una « Nueva cantiga de Santa María de la Arrixaca », inspirée par la cantiga 169 du roi Alfonso X (p. 273). La poésie romantique, spécialement celle d'Espronceda et celle de Bécquer, a également été une lecture profitable des poètes de 27 , auteurs pour plusieurs d'entre eux d'une «extensa nómina » de traductions (à ce sujet voir : FJDR, Las traducciones del 27. Estudio y antología, Fundación José Manuel Lara, 2007). On connaît l'importance des revues poétiques publiées aux quatre coins de l'Espagne par ceux qui n'étaient encore que de jeunes poètes, tous élèves en cela de Juan Ramón Jiménez et de sa revue Índice. 
C'est un panorama très instructif que propose à ce sujet FJDR dans l'étude intitulée « La revista poética en España como excluyente signo generacional (1916-1932)», où il est largement question des Litoral, Verso y Prosa, Carmen ou Papel de Aleluyas (p. 105-122). Si les revues ont permis aux poètes de se lire mutuellement à une époque où l'édition et les communications n'étaient pas ce qu'elles allaient devenir, les anthologies ont, quant à elles, fait connaître les poètes de 27 à l'étranger. Ainsi celles de Prampolini en Italie, de Souvirón au Chili, de Federico de Onís (alors professeur à New York), celle enfin de Mathilde Pomès dans l'aire francophone ("Las antologías de 1934 y la internacionalización de los poetas del 27 », p. 123-141). L'un des traits marquants du groupe de 27 fut le sens de l'humour. Lola. Amiga y Suplemento de Carmen en apporta une riche preuve, sans parler de poèmes tels que la «Serranilla de la jinojepa », parodie burlesque par Gerardo Diego de la fameuse serranilla du marquis de Santillana (« Humorismo y vanguardia en la poesía del $27 »$, p. 77-104). Il est enfin un personnage dont l'œuvre autant que la personne ont fasciné les poètes : Picasso (" La "línea pura": Picasso y los poetas del 27 », p. 63-75).

2 Les dix-huit autres études développent un aspect particulier de chacun des huit poètes de 27 les plus souvent cités par la critique. Il n'est pas étonnant que le professeur que fut Pedro Salinas ait fait alterner son œuvre de critique et celle de poète. On lui doit entre autres des pages fondamentales consacrées à Jorge Manrique, au Poema de Mio Cid ou à Rubén Darío (p.155-185). Professeur, Jorge Guillén le fut aussi. Excellent connaisseur de la culture gréco-latine, on lui doit une belle traduction de Pervigilium Veneris (La Veillée de Vénus), redécouverte par Érasme en 1507 (p. 233). À l'instar de Salinas, Guillén, qui commença sa carrière de professeur universitaire à Murcie avant d'exercer à partir de 1930 à Séville, manifesta dans sa poésie un égal attachement à ces deux villes ("Jorge Guillén: de la luz de Murcia a la de Sevilla», p. 187-229). L'éditeur des œuvres complètes de Gerardo Diego qu'est F. J. Díez de Revenga consacre quatre études au poète de Santander, dont une ( Libertad, consumación y duda: Gerardo Diego, Vicente Aleixandre, Dámaso Alonso », p. 323-341) découvre les convergences et les spécificités de trois poétiques. Le Murcien qu'est Díez de Revenga ne pouvait rester insensible au " precioso soneto [de Gerardo Diego] con referencias directas a Murcia » qu'est «Augurio », dont le premier tercet évoque splendidement la vue sur la Huerta que l'on découvre (ou découvrait...) du haut du clocher baroque de la cathédrale : "Aprende, amigo, goza del Segura. / Sube a la reina torre a distenderte / en círculos de lumbre y de verdura " ("Un soneto de Gerardo Diego ", p. 269-283). Vicente Aleixandre fut lui aussi un grand lecteur de la littérature du Siècle d'Or, en particulier de Lope de Vega, souvent présent dans sa poésie ("Aleixandre y la tradición áurea: Lope de Vega », p. 355-368), mais l'auteur de Espadas como labios fut également un poète militant, traducteur du poème «Pour se faire aimer » de Nancy Cunard, et auteur de l' «Oda a los niños de Madrid, muertos por la metralla ", écrit en 1936, redécouvert et publié par Antonio Fernández Ferrer dans le Bulletin Hispanique en 1981 (vol. 83, n 1-2). Dans "Teatro de García Lorca y canción tradicional: notas a Yerma » (p. 381-402), FJDR montre bien comment Lorca introduit dans son théâtre des chansons traditionnelles en leur confiant une fonction dramatique. C'est ensuite vers le poète que se tourne l'auteur dans une étude approfondie du sonnet «En la muerte de José de Ciria y Escalante» (p. 369-379). Deux études sont consacrées à Luis Cernuda. Ainsi «Luis Cernuda en la órbita de su generación» (p. 427-447), où sont rappelés les quatre traits communs que Cernuda distinguait chez les membres d'un groupe qu'il avait baptisé «Generación de 1925 ». Quelques pages plus loin, Díez de Revenga fait dialoguer le célèbre poème de Vicente Aleixandre « En la plaza » avec « En medio de la multitud» de Luis Cernuda. C'est à celui qui fut le dernier survivant des 
poètes de 27, Rafael Alberti, que sont consacrées les deux dernières études de l'ouvrage. Dans la seconde, qui porte le joli titre de "Melancolías romanas de un poeta otoñal (Rafael Alberti en Roma) ", sont évoquées les amours du poète vieillissant avec une jeune muse catalane, inspiratrice du livre encore inédit Amor en vilo.

3 L'ouvrage de Francisco Javier Díez de Revenga, dont ce compte rendu n'offre qu'un très insuffisant reflet, rendra les plus grands services aux enseignants, aux jeunes chercheurs et aux étudiants. Tous y trouveront une riche leçon de littérature, fruit d'une vie d'étude en grande partie consacrée aux poètes de 27.

\section{AUTEURS}

JACQUES ISSOREL

Université de Perpignan 